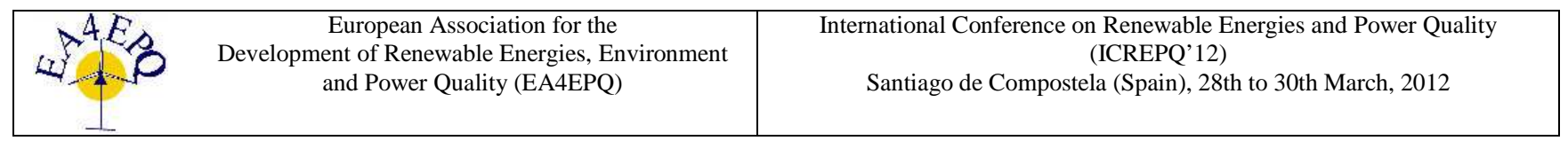

\title{
Reactive Power- and Voltage Regulation in Micro Grids
}

\author{
I. Vokony Student M., IEEE, Dr. A. Dan Senior M., IEEE \\ Department of Electric Power Engineering \\ Budapest University of Technology and Economics \\ Muegyetem rkp. 3. Budapest 1111 (Hungary) \\ Phone/Fax number:+0036 1 463-3030, e-mail: vokony.istvan@ vet.bme.hu, andras.dan@ vet.bme.hu
}

\begin{abstract}
This paper is a continuation of the paper Examination Of Micro Grid Operation In Island Condition, Focusing On Voltage Control [10]. It has presented the assessment of micro grids' voltage and reactive power control. The increasing integration of intelligent energy distribution networks has to serve the interest of the consumers. Therefore it is necessary to examine the quality of the electricity supply with regard to the voltage quality as well. How is it possible to ensure the regulation in those cases e.g. in case of island operation. In the paper the model developed and used for simulating the micro grids is introduced, and it is also shown, how to apply them for island operation assessment. With the help of a model network the results of the simulations are presented and the conclusions are evaluated.
\end{abstract}

\section{Key words}

micro grid, modular structure, SVS, inverter regulation

\section{Introduction}

The increasing integration of smart grids means a lot of new challenges. Up to now the stability, the frequency balance and the reliability of the system were examined. These are the most relevant parameters in aspect of the TSO. Providing the electrical energy continuously and reliable is not enough for the consumers, there are criteria for the quality of the providing as well. The most important standard is the EN50160, which considers for the quality of the provided voltage. So it is unavoidable to examine the issues of the voltage- and reactive power regulation.

First of all let's take the criterion of the global reactive power balance for the whole system.

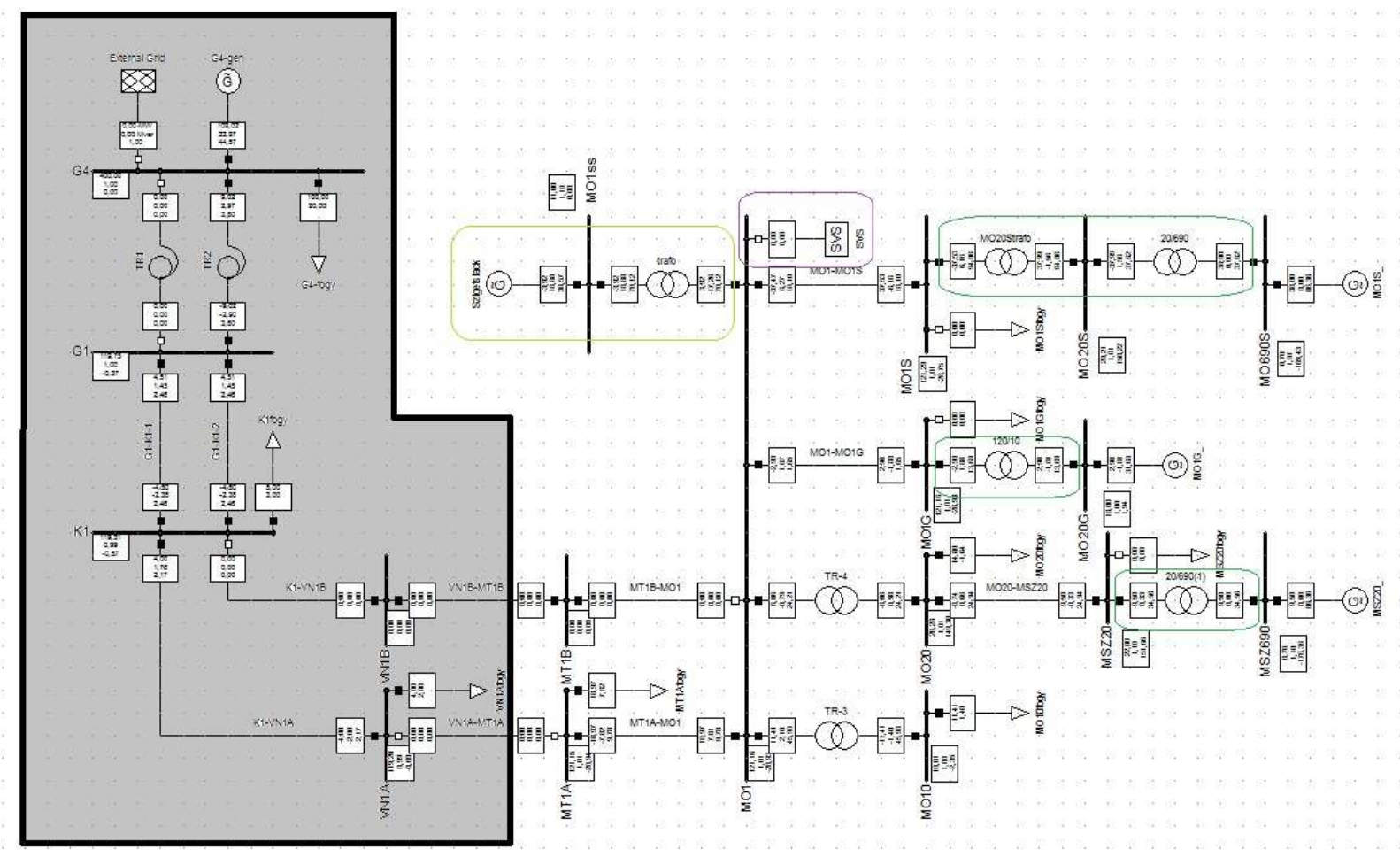

Fig. 1. The model network in DigSilent Power Factory 14. environment 
The balance for the reactive power in a whole- or a part of a system is the next: $\Sigma \mathrm{Q}_{\mathrm{E}}+\mathrm{Q}_{\mathrm{I}}=\Sigma \mathrm{Q}_{\mathrm{F}}+\mathrm{Q}_{\mathrm{H}}$, where:

$\Sigma Q_{E}$ is the amount of the reactive power from the power plants

$\mathrm{Q}_{\mathrm{I}}$ is the balance of the imported reactive power flows (incoming is the positive)

$\Sigma Q_{F}$ is the amount of the substations reactive power consumptions

$\mathrm{Q}_{\mathrm{H}}$ is the amount of the system elements reactive power consumptions (wires, cables, transformers, reactors, static compensators, etc.)

The reactive power flows from the capacitors and overexcited generators called reactive power production, the underexcited generators and inductances reactive power called reactive power consumption. The reactive power is positive, if the current is delaying to the voltage, while the active power is positive compared to the power flows on an arbitrary system element $\mathrm{S}=\mathrm{P}+\mathrm{jQ}$.

These principles considers to the high/middle voltage level systems, but there is no reason to not to use in micro/smart grid systems as well.

\section{The model network}

It was important to create a model which is similar to the reality. So it was useful to pick a part of the system which contains renewable energy sources (wind power park near Mosonszolnok) and capable to island operation. The decision was the area of Mosonmagyaróvár.

The model topology is shown in Fig. 1 which was made by the DigSILENT. The network model consists of:

- $\quad$ high- and middle voltage lines

- $\quad$ and buses (400-120-20 and 10-kV)

- transformers

- $\quad$ lines, parallel-lines

generators and loads.

The consumers of the area were modeled by two nodes: the cabled consumers at $10 \mathrm{kV}$ (MO10) and the wired consumers at $20 \mathrm{kV}$ (MO20). The other industrial consumers are connected to the K1-MO1 120kV parallel line.

The grid operates in island during the examinations. The former results confirmed that it is possible. In these examinations not time-domain than static load-flow runs were simulated.

There was a need for a slack machine to help the simulators iteration during extreme scenarios. This machine was connected to MO1 $120 \mathrm{kV}$ bus and called Szigetslack.

An SVS (static var system) was modeled as well. The static var compensator system is a combination of a shunt capacitor bank and a thyristor controlled shunt reactance. The capacitors in the capacitor bank can be switched on and off individually. The capacitors could be switched with thyristors (TSC) or could be permanently (mechanically) connected (MSC) (Fig. 2).

The static VAr system is important for controlling the voltage at the direct connected busbars or at a remote busbar. The capacitors may be switched on and off, depending on the load situation, in response to changes in reactive power demands. The thyristor controlled reactor fine-tunes the reactive power delivered by the static var system.

A SVS can produce a part or all of the reactive power demand of nearby loads. That reduces the line currents necessary to supply the loads; turn in this reduces the voltage drop in the line as the power factor is improved. Because the static var systems lower the reactive requirements from generators, more real power output will become available.

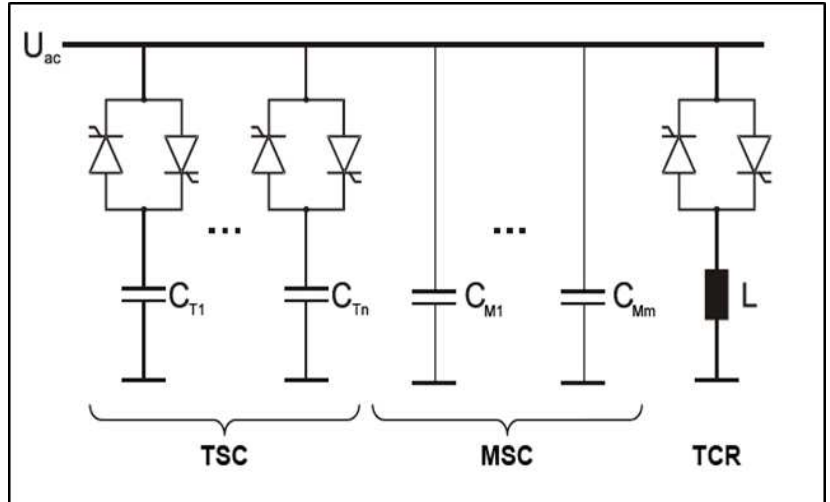

Fig. 2. Static VAr System Model

\section{Evaluating the simulation results}

Load-flow runs were simulated during the examinations. The voltage values formed by the reactive power flows in case of different load conditions were looked for. For these examinations the producer/consumption profiles have to be known.

\section{A. Input parameters}

The consumers profile was calculated by real measured data which are from national load measure results (19.01.2011.). So, hourly profiles for the consumptions were ready to use.

To create the profiles of the wind power plants were much more difficult. The production data were given for that day, but the wind power plants behavior are really various. We decided to simulate load-flow from 0 to 24 hours with the known profiles for production and consumption, while the production of the wind power plants were changed from $0 \%$ to $100 \%$. The wind speed was changed linear so the wind power plant profile was the next (Fig. 3):

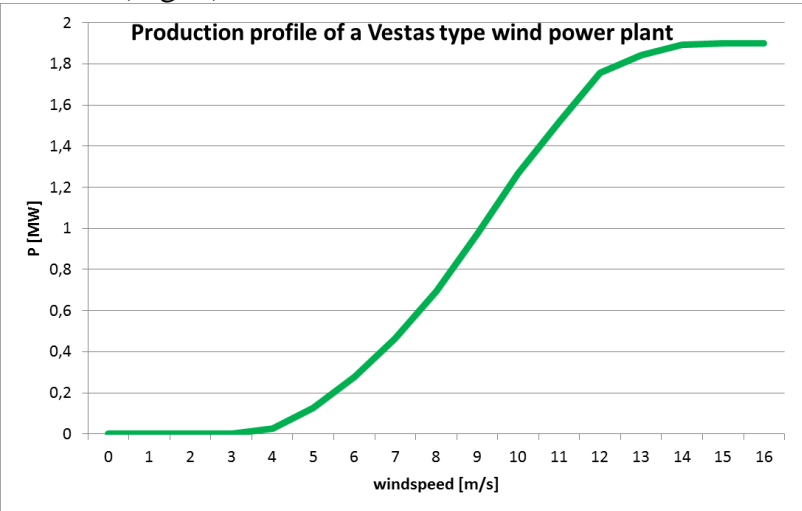

Fig. 3. Wind power plant profile 


\section{B. The effect of the SVS to the voltage - reactive power balance}

The static VAr system is important for controlling the voltage at the direct connected busbars or at a remote busbar. The capacitors may be switched on and off, depending on the load situation, in response to changes in reactive power demands. In our case the voltage of the central bus is regulated to $126 \mathrm{kV}$.

By changing the production of the wind power plants from $0 \%$ to $100 \%$ the system slack machine has to provide the active and reactive power balance in the grid.

At Fig. 4 and 5 can be seen the reactive power of the slack machine in consideration of the SVS.

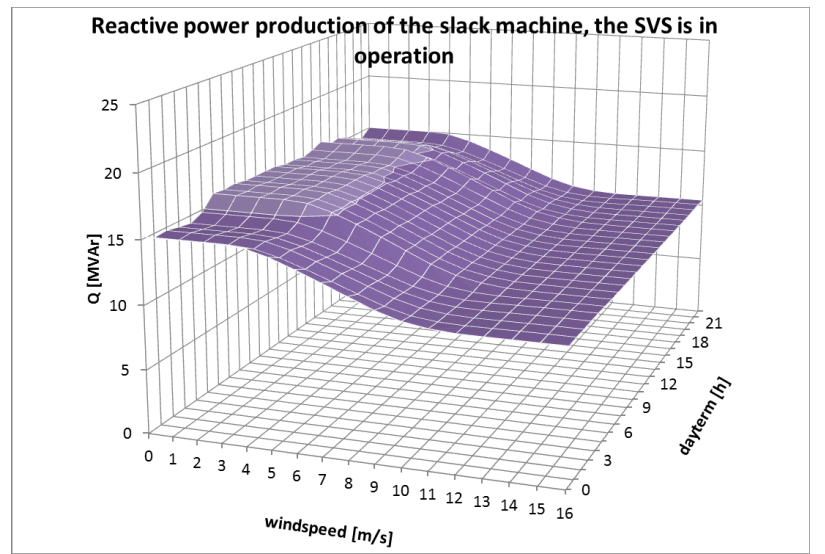

Fig. 4. Reactive power from system slack with SVS

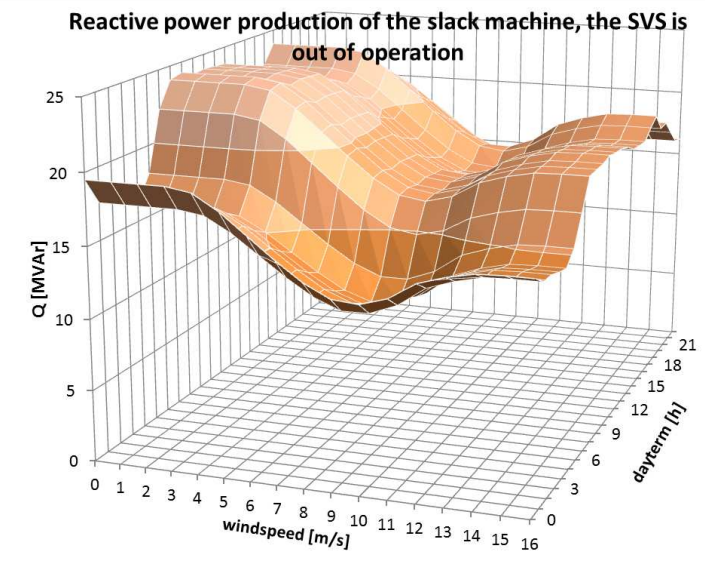

Fig. 5. Reactive power from system slack without SVS

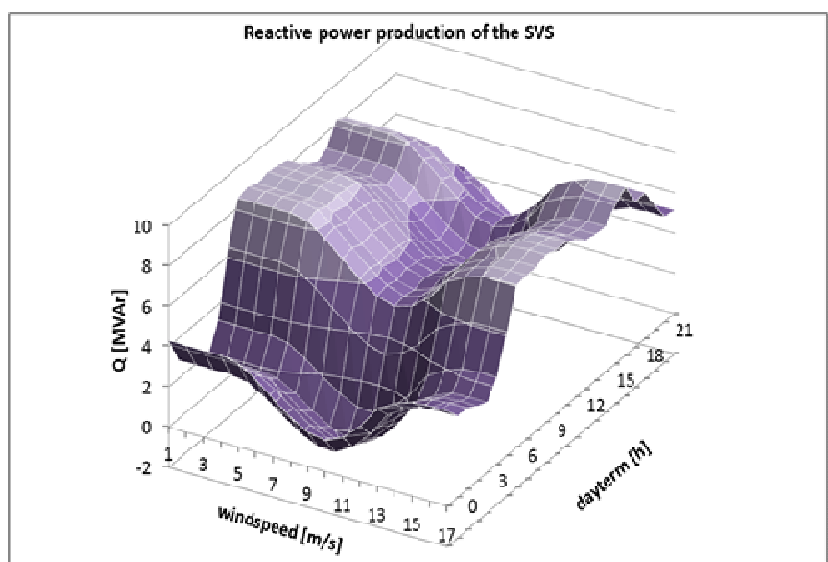

Fig. 6. SVS reactive power for regulation
It can be seen that the slack machine's reactive power is decreasing monotonous during the wind speed - so the generated power by the wind power plants - is rising while the SVS is in operation. The consumers profile can be well followed up.

A reactive power valley can be seen in Fig. 5 and 6 independently by the consumers profile in the near of $10 \mathrm{~m} / \mathrm{s}$ wind speed. This negative peak on Fig. 5 is in the slack machine reactive power production. In this case the SVS is out of operation. In case of SVS operation this negative peak will appear in the reactive power production of the compensator.

This reactive power change will occur in the voltage levels as well (Fig. 7).

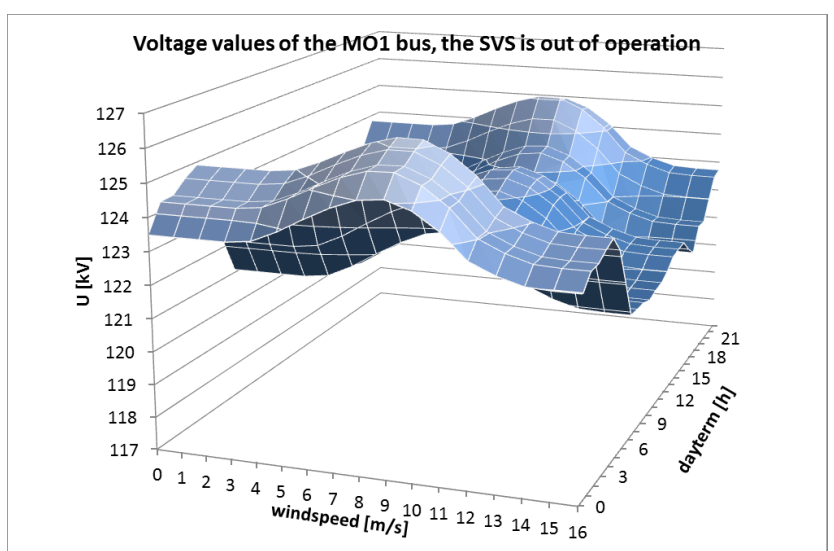

Fig. 7. The voltage changes of the central bus (MO1)

Our expectation was that the increasing wind speed will cause increasing wind power generation. Because of the increasing flowing active power the transformers reactive power need will raise as well. These changes are not linear but monotonous events. Nevertheless a sign change was showed by the simulations. The reason is in the topology.

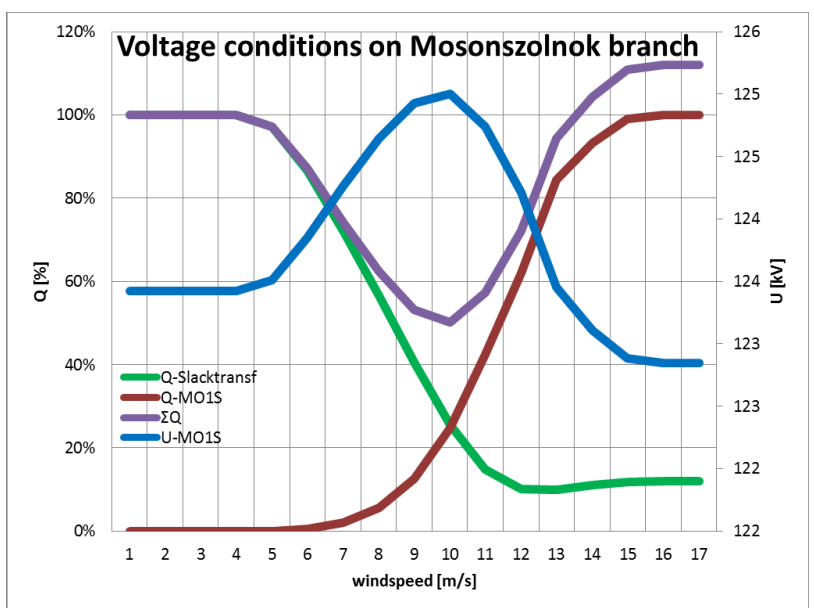

Fig. 8. The answer to the sign change

As the 3D figures show the local voltage peak is independent of the dayterm. It is present in the central bus voltage as well, which cause +/- 5-7\% voltage fluctuation on the other busses too.

Results for a specific hour were analyzed step by step. The increase of the wind power will increase the reactive power need on the MO1S branch, so the reactive power consumption of the $120 / 20 \mathrm{kV}$ transformer. Meanwhile 
the slack bus has to provide less active power, so its block transformer reactive power need will decrease. (It is marked with purple in Fig. 8). The amount of reactive power will reach a local minimum caused by the topology and the cross-flows, which results increase of the voltage level.

\section{The effect of the gas turbine to the voltage - reactive power balance}

Another effect was examined during the simulations as well: how influences the coating of the MO1G gas turbine into the reactive power regulation - meanwhile making its node voltage constant - the voltage conditions of the island. The preliminary examinations showed that in some cases the voltage limits (+/- 10\%) will be reached. It was the most specific at the MSZ20 bus. 5 pieces of $2 \mathrm{MW}$ nominal power wind plants are connected to this bus.

At $100 \%$ wind power production the voltage of this bus can reach the $114 \%$ of the nominal voltage. This amount of voltage level can cause failures. In this case the constant voltage level at the gas turbine seems to be useful. The reactive power production of the MO1G gas turbine can be seen at Fig. 9.

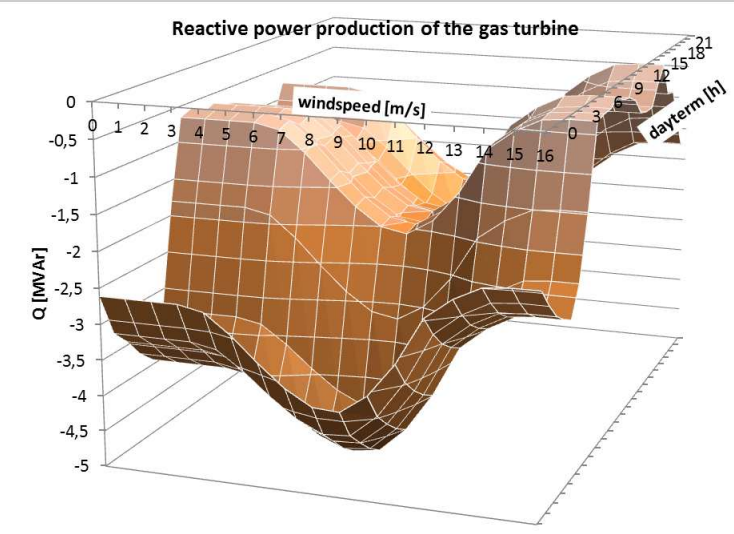

Fig. 9. MO1G gas turbine reactive power consumption

At the moment of the voltage peak the gas turbine consumes reactive power to hold the constant nominal voltage level. So the voltage level of the MO1 bus will converge to the nominal value like the MSZ20 bus too. Without the MO1G voltage regulation the voltage of the MSZ20 bus changes during the day between $4,8 \%$ and $14,4 \%$, and with the MO1G voltage regulation these limits are $0,1 \%$ and $10,9 \%$. The upper limit is a bit higher than in the standards, but less than $1 \%$. The voltage fluctuation is increased by this solution, as it can be seen at Fig. 10 and 11.

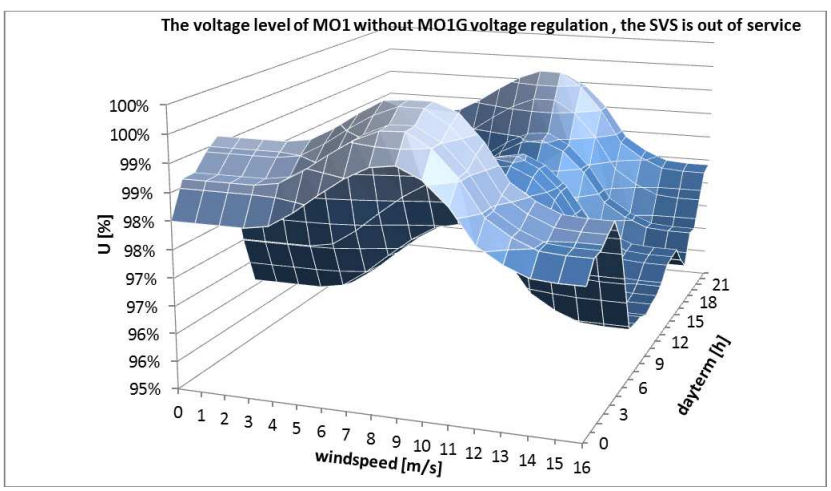

Fig. 10. Voltage fluctuation of MO1 without regulation

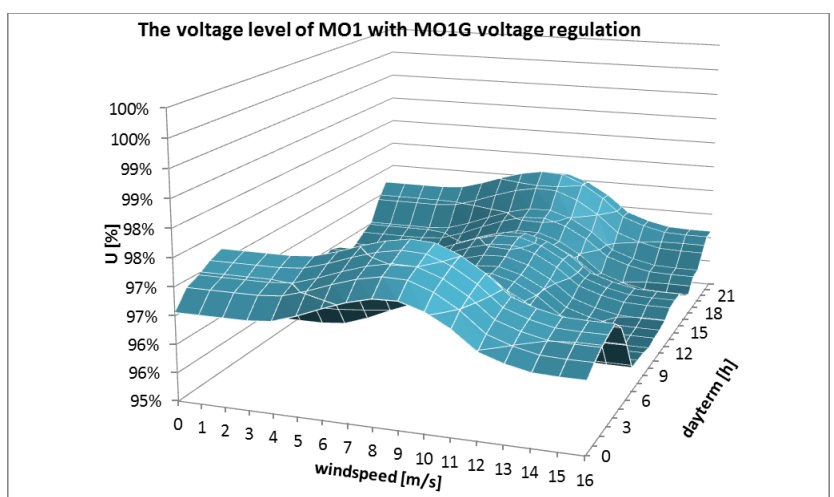

Fig. 11. Voltage fluctuation of MO1 with the help of MO1G

\section{The effect of the wind power park to the voltage - reactive power balance}

The last part of these examinations was changing the power factor $(\cos \varphi)$ of the wind power plants so thereby involve them into the voltage reactive power regulation. The new wind power plants are connected to the system via power electronic devices. The power factor can be changed by the inverter thereby the reactive power production is variable. The problem was mentioned in 3./B. could be solved as follows: as the active power increases at the wind power plants the reactive power production will increase as well. In that way with the inverters the appropriate reactive power production can be set. In consideration that the production is at $120 \mathrm{kV}$ the power factor was set to $\cos \varphi=0,95$. The reactive power production of the system slack machine is increasing while the SVS is out of service; it can be seen in Fig. 12. It means that the system slack produce even less reactive power for its block transformer, and the wind power plants produce even more for their transformers needs.

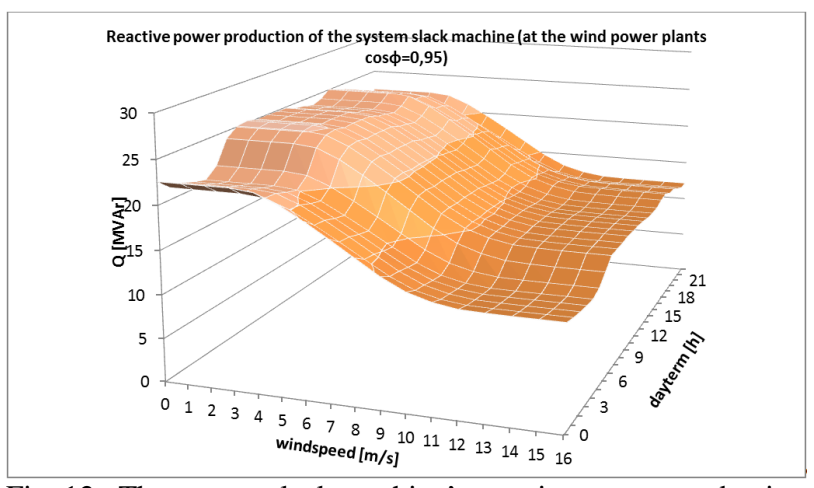

Fig. 12. The system slack machine's reactive power production 
And this solution will help at the other nodes as well: for example the voltage fluctuation of the central bus ceased and the voltage peak disappeared (Fig. 10). The MO1 bus voltage changes can be seen at Fig. 13. The producers/consumers profile are detectable and the changes are monotonous.

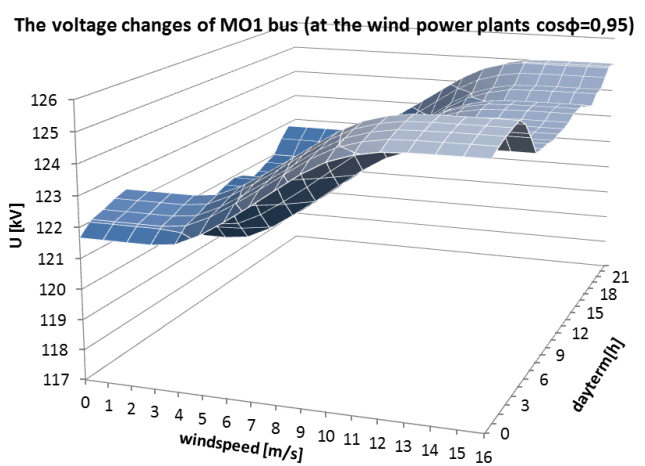

Fig. 13. The voltage changes at MO1 bus with the wind power plants reactive power regulation

\section{Summary, future plans}

Up to now the micro/smart grids were examined from different points of view. In which circumstances is possible to hold the stable operation or the island operation. For the appropriate operation it is necessary to provide the quality criteria, hold the voltage level near to the nominal.

In this paper three influences were examined. First of all the effect of an active compensator, than the effect of a gas turbine using it for reactive power- voltage regulation, and at least the wind power plants were used for voltage control by the inverters.

As the gas turbine so the active compensator are optimizing the voltage levels in the grid. The greater fluctuation is at MSZ20 bus, more than $10 \%$. Using the reactive power- voltage regulation methods the fluctuation is increasing and the excess is almost between the limits.

It is worth to evolve the operation avoiding the crossflows, i.e. the opposite flow of active- and reactive power.

It is expedient to realize the reactive power needs at local levels.

General conclusions:

- the topology, the places of the active compensators and the power flows are definitive in voltage control

- scaling of the transformers are really important: the voltage conditions are influenced by the reactive power needs of the overloaded transformers

- it is better to provide the reactive power needs of the consumers locally

- the solution for these problems could be one or more SVS at the appropriate places; or using the synchronous machines in the reactive powervoltage regulation

- it is really effective to provide the reactive power locally by the power electronics
Concluding the results it is necessary to draw up a defined framework which is an effective support in case of island operations in micro/smart grids.

\section{Acknowledgement}

This work is connected to the scientific program of the " Development of quality-oriented and harmonized $\mathrm{R}+\mathrm{D}+\mathrm{I}$ strategy and functional model at BME " project, supported by the New Hungary Development Plan (Project ID: TÁMOP-4.2.1/B-09/1/KMR-2010-0002).

\section{References}

[1] Voltage Control in Smart Grids: An Approach Based on Sensitivity Theory Morris Brenna, Ettore De Berardinis, Federica Foiadelli, Gianluca Sapienza, Dario Zaninelli. J. Electromagnetic Analysis \& Applications, 2010, 2, 467474

[2] Electrical Stability of Large Scale Integration of Micro Generation Into Low Voltage Grids, Xueguang Wu, Yibin Zhang, Atputharajah Arulampalam, Nick Jenkins. International Journal of Distributed Energy Resources Volume 1 Number 4 (2005) Pages 279-298

[3] DIgSILENT PowerFactory Version 14.0 Manual', 2008

[4] Anca D. Hansen - Clements Jauch - Poul Sorensen Florin Iov - Frede Blaabjerg: Dynamic wind turbine models in power system simulation tool DIgSILENT, Roskilde, Denmark, 2003

[5] Támogatandó-e a szélenergia hasznosítása Magyarországon? 2.rész, Dr. Hunyár Mátyás, Dr. Veszprémi Károly, Elektrotechnika 2010/05, Budapest

[6] Technical And Economic Feasibility of Microgrid-Based Power Systems Phil Barker, Doug Herman. Seventh EPRI Distributed Resources Conference and Exhibition Dallas, TX March 20-22, 2002

[7] Daniel Kirschen: Towards Decentralised Power Systems. ECCE meeting in Bruxels, oct. 2003

[8] Khaled A. Nigim, Wei-Jen Lee: Micro Grid Integration Opportunities and Challenges. IEEE 2007 General Meeting, Tampa, USA, 24-28 June 2007

[9] A. Faludi, L. Szabo: Power System Operation and Control (Hungarian) Lecture notes on vet.bme.hu/okt/foszak/ver/veri/index.htm, Budapest 2002.

[10] I. Vokony, A. Dán: Examination Of Micro Grid Operation In Island Condition, Focusing On Voltage Control, Electrical Engineering, Electronics, Automatics, issue 58, no.2, 2010, pages 15-19. 